\title{
Substitution effect of renewable portfolio standards and renewable energy certificate trading for feed-in tariff
}

\author{
Qi Zhang ${ }^{\mathrm{a}, *}$, Ge Wang ${ }^{\mathrm{a}}$, Yan $\mathrm{Li}^{\mathrm{a}}$, Hailong $\mathrm{Li}^{\mathrm{b}}$, Benjamin McLellan ${ }^{\mathrm{c}}$, Siyuan Chen ${ }^{\mathrm{a}}$ \\ a Academy of Chinese Energy Strategy, China University of Petroleum-Beijing, Changping, Beijing 102249, China \\ b School of Business, Society and Technology, Mälardalens University, Sweden \\ ${ }^{c}$ Graduate School of Energy Science, Kyoto University, Japan
}

\section{H I G H L I G H T S}

- The substitution effect of RPS and REC trade for the FIT was calculated and analyzed.

- A multi-region power market model was proposed and developed.

- REC trade can reduce the government's expenditure on subsidies for renewable energy.

- FIT subsidy provides guarantees of the local power sectors' profit.

- RPS, REC trade and FIT subsidy need to be considered together.

\section{A R T I C L E I N F O}

\section{Keywords:}

Renewable portfolio standard

Renewable energy certificate

Feed-in tariff

Subsidies

\begin{abstract}
A B S T R A C T
The Feed-in Tariff (FIT) has been successfully used to promote the development of renewable energy; nevertheless, it may cause financial burden on the governments at the same time. Compared with FIT, Renewable Portfolio Standards (RPS) and the Renewable Energy Certificate (REC) trading have been considered to reduce the government's expenditure caused by the subsidization. To examine the effectiveness of RPS and REC trading, the development of renewable energy and the environmental and economic benefits under different policies have been quantitatively investigated by using a multi-region power market model and China has been chosen as a case study. The obtained results show that: (i) REC trading can efficiently reduce the government's expenditure on subsidies for the development of renewable energy; (ii) Compared to FIT, RPS and REC trading will reduce the power sectors' profit; and (iii) RPS and REC trading may not be enough to achieve the target on renewable energy especially when the capital cost is high, therefore, RPS, REC trade and FIT subsidy should be implemented as complementary policies, not independent.
\end{abstract}

\section{Introduction}

Growing concern regarding climate change requires reducing greenhouse gas emissions and promoting the development of renewable energy, in which policies are playing a key role. To date, the most common and successful policies include Feed-In Tariffs (FITs) and Renewable Portfolio Standards (RPS) [1]. The impacts of FITs and RPSs have been widely studied [2-6]. FITs are regarded as more efficient because they provide long-term financial stability for investors [7]. However, the fast growing of the government's expenditure on subsiding renewable energy has long been regarded as parts of the social welfare change [8] without considering the public's willingness-to-pay, resulting in heavy financial burdens for governments all over the world.
In Spain the FIT for PVs stopped in 2012 due to generous tariffs, overcapacity and tariff deficits. And in other EU countries, the FIT schemes also have been sharply reduced partly due to the financial recession [9]. Recent studies in China have also clearly shown different opinions of public's willingness $[10,11]$ about current FIT, which is so high that tens of billions RMB subsidies have not been delivered in a timely manner in recent years. In order to relieve the financial pressure caused by subsidies, RPS and REC trade are alternatives for jurisdictions. Different from the FIT policy that pays a fixed price for renewable power generation, RPSs incentivize generators to produce a minimum proportion of eligible renewable power in their supply mix. Meanwhile, by linking eligible renewable energy to Renewable Energy Certificates (RECs), power utilities are required to obtain enough RECs in order to

\footnotetext{
* Corresponding author

E-mail addresses: zhangqi@cup.edu.cn, zhangqi56@tsinghua.org.cn (Q. Zhang).
} 


\section{Nomenclature}

Subscripts

D representative days (3 typical days are used)

$H \quad$ time series $(1-8)$

$R, R^{\prime} \quad$ regions (Northeast, North, Shandong, East, Fujian, South, Chuanyu, Central, Northwest and Xinjiang)

NG technologies not eligible for RPS (Coal, Gas, Nuclear and Hydro)

$R G \quad$ technologies eligible for RPS (PV and Wind)

\section{Parameters}

$N G B P P_{N G}$ regulated benchmark power price of NG power (billion $\mathrm{RMB} / \mathrm{GWh}$ )

$R G F I T_{R G}$ feed-in tariff of RG power (billion RMB/GWh)

$R P S_{R} \quad$ RPS target for region $\mathrm{R}(\%)$

$D R \quad$ discount rate (\%)

$N G F C_{N G}$ fixed cost for new NG capacity (billion RMB/GW)

$R G F C_{R G}$ fixed cost for new RG capacity (billion RMB/GW)

$N G V C_{N G}$ fuel cost for generated NG power (billion RMB/GWh)

$N G M C_{N G}$ operation and maintenance cost of installed NG capacity (billion RMB/GW)

$R G M C_{R G}$ operation and maintenance cost of installed RG capacity (billion RMB/GW)

$R G C F_{D, H, R, R G}$ maximum hourly capacity factor of RG power (\%)

$I N I N G_{R, N G}$ initial NG capacity (GW)

$I N I R G_{R, R G}$ initial RG capacity (GW)

$N G T_{R}$ regional maximum total installed capacity of NG power (GW)

$R G T_{R} \quad$ regional maximum total installed capacity of RG power

\section{(GW)}

$N G U P C F_{N G}$ upper limit of annual capacity factor of NG power (\%)

$N{ }^{\prime} L O C F_{N G}$ lower limit of annual capacity factor of NG power (\%)

$N G U P_{N G}$ upper limit of hourly capacity factor of NG power (\%)

$N G L O_{N G}$ lower limit of hourly capacity factor of NG power (\%)

$R A M P U P_{N G}$ maximum ramp up rate of NG power (\%)

$R A M P D N_{N G}$ maximum ramp down rate of NG power (\%)

$D E M_{D, H, R}$ regional hourly power demand (GWh)

$T E F_{R, R^{\prime}} \quad$ interregional transmission efficiency (\%)

$T V C_{R, R^{\prime}} \quad$ variable cost of interregional transmission (billion RMB/ GWh)

$T R C_{R, R^{\prime}} \quad$ interregional transmission grid capacity (GW)

Variables

newng $_{R, N G}$ new installed NG capacity (GW)

newrg $_{R, R G}$ new installed RG capacity (GW)

$n g p p_{D, H, R, N G}$ hourly generated NG power (GWh)

$\operatorname{rgpp}_{D, H, R, R G}$ hourly generated RG power (GWh)

$p p f_{D, H, R, R^{\prime}}$ hourly power purchase from region $R^{\prime}$ (GWh)

pst $_{D, H, R, R^{\prime}}$ hourly power sold to region $R^{\prime}$ (GWh)

$\operatorname{recpf}_{R G, R, R^{\prime}}$ annual REC purchased from one region (GWh)

recst $_{R G, R, R^{\prime}}$ annual REC sold to one region (GWh)

powpri $_{D, H, R, R^{\prime}}$ interregional power trade price (billion RMB/GWh)

recpri $_{R G, R, R^{\prime}}$ interregional REC trade price (billion RMB/GWh)

\section{Abbreviation}

RPS Renewable Portfolio Standard

FIT Feed-in tariff

REC Renewable Energy Certificates

LPS Local Power Sector meet the regulations. RECs can be traded and therefore bring economic incentives for cost-effective renewable production, which is not covered by the government. This paper is to study the effectiveness of using RPS and REC trading to replace FIT, and their synergistic effects on government expenditure, power utilities' profits and regional renewable energy development. Therefore, the authors proposed a model, which can be used for all nations to quantify the substitution effects of RPS and REC trade for FIT. As a case study, the model has been applied to China, who has just announced a REC trading system in 2017, following the first national RPS targets published by the National Energy Administration in 2016 with detailed 2020 targets at province level [12].

Many studies have been done to investigate the effect of RPS and FIT on promoting the development of renewable energy. However, from different perspectives, different conclusions may be obtained. From the viewpoint of renewable energy industries, FIT, which can provide a stable and profitable market, is more favorable than RPS, which may create a market uncertainty and lower overall profit [13-15]. On the contrary, from the viewpoint of social welfare, a RPS is more preferred because it introduces market competition into the renewable energy field [16]. However, few of these studies focus on the government's fiscal interests. Since renewable power and non-renewable power are homogeneous, it is difficult to pass the cost of renewable power onto consumers by the market. Thus, the government has to afford the expenditure directly.

The RPS policy and REC trading have also been widely examined. Mack et al. [17] and Berendt [18] have argued that the lack of liquidity of the existing REC markets in the U.S. leads to volatile and reducedvalue markets for renewable energy certificates and ultimately increases the cost of renewable energy. Perez [19] found that a $25 \%$ outof-state REC allowance can capture most of the economic benefits, and further increasing REC trading flexibility contributes only slightly.
These studies provide evidence of the efficiency of a free trading market for REC. However, empirical evidence from Yin [20] showed that allowing free trading of RECs can significantly weaken the impact of RPS for the regions lacking renewable resources. Such contrary opinions put a question mark on whether REC trading is suitable for all situations when adopting an RPS.

To analyse the effect of FIT and RPS with/without REC trading, many models have been developed, which can be divided into three types:

(i) Computable General Equilibrium (CGE) models: for example, Morris [21] revised Emissions Prediction Policy Analysis (EPPA) model, which is a multi-region, and multi-sector recursive-dynamic representation of the global economy. In the EPPA model, different electricity generation technologies are modeled as different sectors in order to investigate the impact of RPS policy on the power mix. However, the time step used in the CGE models is usually a month or a year, and therefore, the impact of the intermittence of renewable electricity generation on the hourly operation of the power system cannot be well considered;

(ii) Optimization models: for example, Perez et al. [19] utilized a power planning model to optimize the portfolio of transmission and generation investments. However, in such models, both the electricity price and the REC price are set as exogenous. The power generators, retailers and consumers are price-takers rather than players in the market, which means that their behaviors have no impacts on electricity price and REC price;

(iii) Complementarity market models: for example Tanaka [22] developed an analytical dominant firm-competitive fringe model to account for market power, and Chen et al. [23] presented an equilibrium market model with both analytical and numerical results 
and the REC price being given endogenously. However, such models are partial equilibrium models and they are unable to analyze the spill-over effect of the power industry on other industries and macro-economy.

Since there is no historical data of REC price in China, an endogenous price derived from the equilibrium REC trading market is essential to quantitatively analyze the effect of the upcoming REC trading. Considering the aforementioned problems, this study is going to develop a multi-region power market model based on the complementarity market model to analyze the regional impacts of RPS, REC trade and FIT. The optimization of power system's hourly operation and the development pathway are considered together with the equilibrium of power market and REC market in this model. As a compromise, the spill-over effect of the power market will not be explored.

China is characterized as extremely uneven geographic distributions in both energy consumption and renewable energy resources. The RPS target allocation in China is tightly correlated to the renewable resource potential, and thus the target is higher in the northern and western provinces and lower in eastern and southern provinces. However, the eastern and southern provinces, with the majority of electricity consumption, will still incur large costs for meeting the RPS target by developing renewable energy. Therefore, intuitively, a nation-wide free REC trading will motivate eastern and southern provinces to import RECs from northern and western provinces. In this way, the renewable projects in northern and western provinces can be supported by the capital from eastern and southern provinces rather than by the FIT subsidy from the government. However, to what extent the RPS and REC trading can substitute the FIT and the spill-over effects of these policies still need to be studied.

The remainder of this paper is organized as follows: Section 2 introduces the multi-region power market model used to study the impacts of RPS, REC trading and FIT in China; Section 3 presents the utilised data of China's regional power sectors, basic assumptions and scenario settings; the results under different policy scenarios are given in Section 4, which is followed by the conclusions in Section 5.

\section{Multi-region power market model}

The proposed multi-region power market model with regional RPS targets is applied to the case study of China's power market up to 2020 considering the RPS targets published by China National Energy Administration. Power generation from different resources, including nuclear, coal, natural gas, large-scale hydro, PV and wind, were considered, while PV and wind power are the sources considered eligible for meeting the RPS.

\subsection{Model structure}

In the proposed model, China's power sector is divided into 10 regions, reflecting the current physical structure of regional high voltage transmission networks [24]. As shown in Fig. 1, the 10 regions are Northeast (Heilongjiang, Jilin, and Liaoning), North (Beijing, Tianjin, Hebei, Shanxi, and Inner Mongolia), Shandong, East (Shanghai, Jiangsu, Zhejiang, and Anhui), Fujian, South (Guangdong, Yunnan, Guizhou, and Guangxi), Chuanyu (Sichuan and Chongqing), Central (Jiangxi, Hubei, Hunan, and Henan), Northwest (Shaanxi, Gansu, Ningxia, and Qinghai) and Xinjiang. Here, Hainan, Tibet, Hong Kong, Macau and Taiwan were not considered, as they have independent grids or small regional power demands.

A RPS is considered with the target for each region, which varies with the renewable energy potentials according to the document published by the National Energy Agency [12]. The target need to be fulfilled for each region, and the regions can fulfil their targets by either generating renewable electricity from local projects or purchasing RECs externally, whereas the corresponding renewable electricity does not have to be delivered with the RECs. The generated renewable power that is counted as the tradeable RECs cannot receive the corresponding feed-in tariff subsidy [25], which can be considered as the cost of REC.

In each region, there is one agent representing the local power sector (LPS), which is the integration of the local power generators and retailers. The LPSs are obliged to meet the regional RPS targets and try to maximize their own discounted profit by deciding on power expansion pathways and operation modes, and trading in the interregional

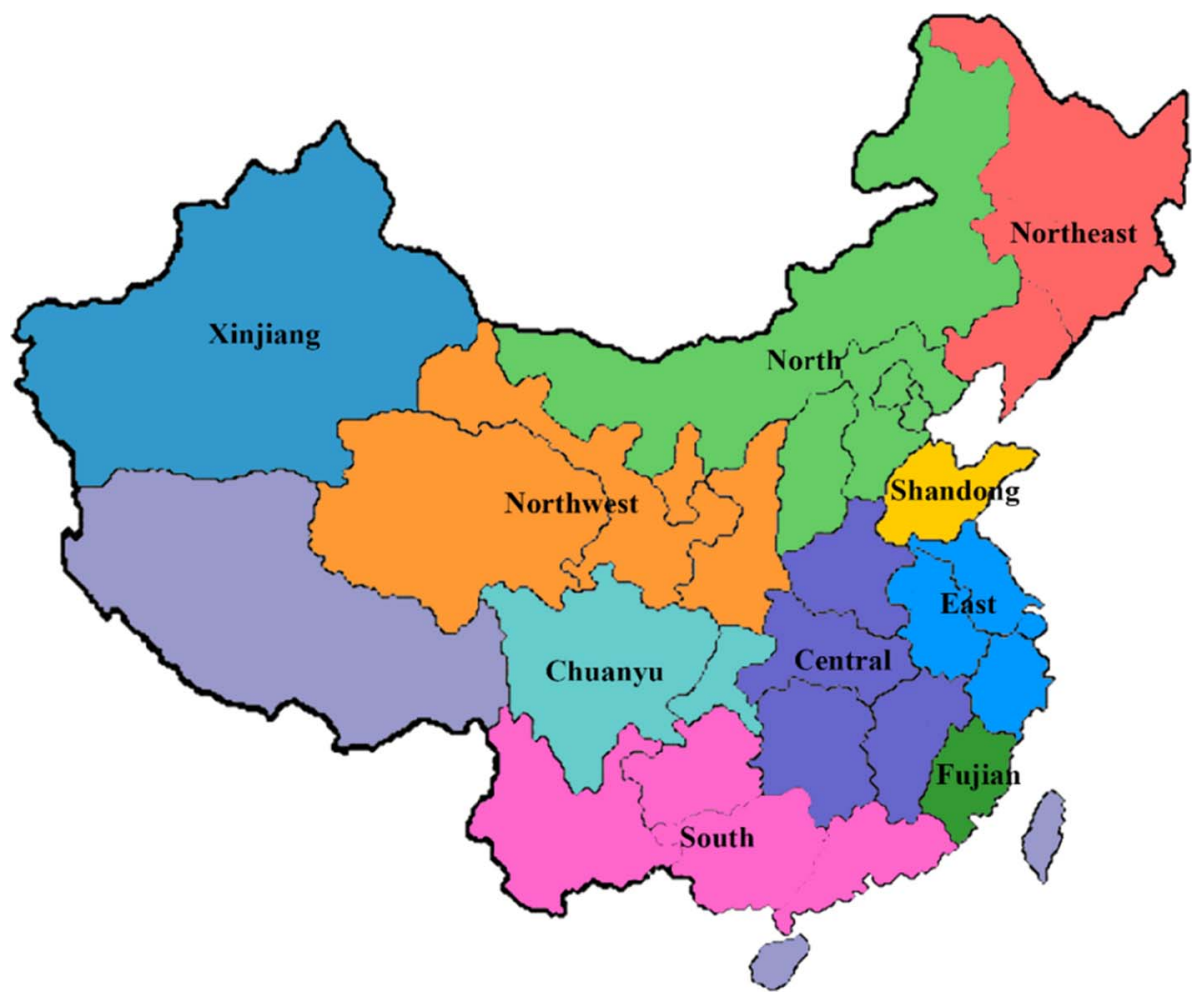

Fig. 1. Regional power sector division of China. 
power market and REC market. LPSs interact with each other by influencing interregional power prices and REC prices.

\subsection{Local power sector}

\subsubsection{Objective function}

The electricity retail price for end-users is fixed and regulated in China and the regional power demand is therefore assumed to be exogenous. Moreover, the benchmark power price for the power generated from different resources are also regulated. The objective of maximizing profit is thus expressed as Eq. (1). The profit includes six parts, which are the net revenue of interregional trading of electricity $\left(\pi_{\text {ELETRADE }}\right)$, the net revenue of interregional trading of RECs $\left(\pi_{\text {RECTRADE }}\right)$, and the net revenue from benchmark power price $\left(\pi_{\text {ELEGEN }}\right)$, minus the capital costs for new installed power capacity $\left(C_{F I X}\right)$, the O \& M (operation and maintenance) costs for non-renewable and renewable power plants $\left(C_{O M}\right)$ and the cost of REC $\left(C_{R E C}\right)$, as depicted in Eqs. (2)-(7).

$$
\begin{aligned}
\max \text { profit }_{R}= & C_{O M}-C_{R E C} \\
\pi_{E L E T R A D E}= & \sum_{D, H, R^{\prime}}\left[p s t_{D, H, R, R^{\prime}} \times \operatorname{powpri}_{D, H, R, R^{\prime}}-p p f_{D, H, R, R^{\prime}} \times\left(\operatorname{powpri}_{D, H, R^{\prime}, R}\right.\right. \\
& \left.\left.+T V C_{R^{\prime}, R}\right)\right] \times D A Y S_{D} \times D R \\
\pi_{R E C T R A D E}= & \sum_{R G, R^{\prime}}\left(\operatorname{recst}_{R G, R, R^{\prime}} \times \operatorname{recpri}_{R G, R, R^{\prime}}-\operatorname{recpf}_{R G, R, R^{\prime}} \times \operatorname{recpri}_{R G, R^{\prime}, R}\right) \\
& \times D R \\
\pi_{E L E G E N}= & \sum_{D, H}\left[\sum_{N G}\left(N G B P P_{N G}-N G V C_{N G}\right) \times n g p p_{D, H, R, N G}\right. \\
& \left.+\sum_{R G} R G F I T_{R G} \times r g p p_{D, H, R, R G}\right] \times D A Y S_{D} \times D R
\end{aligned}
$$

$C_{F I X}=\left(\sum_{N G} N G F C_{N G} \times\right.$ newng $\left._{R, N G}+\sum_{R G} R G F C_{R G} \times n e w r g_{Y, R, R G}\right) \times D R$

$C_{O M}=\left[\sum_{N G} N G M C_{N G} \times\left(I N I N G_{R, N G}+\right.\right.$ newng $\left._{R, N G}\right)+\sum_{R G} R G M C_{R G}$ $\times\left(I N I R G_{R, R G}+\right.$ newrg $\left.\left._{R, R G}\right)\right] \times D R$

$C_{R E C}=\sum_{R G}\left(R G F I T_{R G}-N G B P P_{C O A L}\right) \times \sum_{R^{\prime}} \operatorname{recst}_{R G, R, R^{\prime}} \times D R$

\subsubsection{Main constraints}

As depicted in Eq. (8), the electrical demand of a region is met by the supply from LPSs, which equals the sum of non-renewable and renewable electricity generation within the region considering the electricity transmitted in and out of the region and the corresponding transmission losses. The constraint to interregional transmission due to technological and infrastructure is considered by setting a transmission capacity, which is shown in Eq. (9).

$$
\begin{aligned}
& \sum_{N G} n g p p_{D, H, R, N G}+\sum_{R G} \operatorname{rgpp}_{D, H, R, R G}+\sum_{R^{\prime}}\left(p p f_{D, H, R, R^{\prime}} \times T E F_{R^{\prime}, R}-p s t_{D, H, R, R^{\prime}}\right) \\
& \quad=D E M_{D, H, R} \\
& p p f_{Y, R, R^{\prime}} \leqslant T R C_{R^{\prime}, R}
\end{aligned}
$$

Power plants are expanded and operated under resource, technical and policy constraints, which can be represented by the limitation on hourly capacity factors. The capacity factor constraints for non-renewable and renewable power plants are shown in Eqs. (10) and (12), respectively. The capacity factor constraints for renewable power plants rooted in the weather condition. And the policy regulation of a minimum annual capacity factor for non-renewable power generators is formulated as Eq. (11)
$\left(I N I N G_{R, N G}+\right.$ newng $\left._{R, N G}\right) \times N G L O_{N G} \leqslant n g p p_{D, H, R, N G} \leqslant$

$$
\left(I N I N G_{R, N G}+\text { newng }_{R, N G}\right) \times N G U P_{N G}
$$

$$
\begin{aligned}
\left(I N I N G_{R, N G}+\text { newng }_{R, N G}\right) \times & N G L O C F_{N G} \times 8760 \leqslant \sum_{D, H} \operatorname{ngpp}_{D, H, R, N G} \\
& \times D A Y S_{D} \leqslant\left(I N I N G_{R, N G}+\text { newng }_{R, N G}\right) \\
& \times N G U P C F_{N G} \times 8760
\end{aligned}
$$

$\operatorname{rgpp}_{D, H, R, R G} \leqslant\left(I N I R G_{R, R G}+\right.$ newrg $\left._{R, R G}\right) \times R G C F_{D, H, R, R G}$

The total installed capacity of the power generated from each resource has an upper limit because of the limited resource of hydro, nuclear and renewable energy, which is described by Eqs. (13) and (14).

$I N I N G_{R, N G}+$ newng $_{R, N G} \leqslant N G T_{R}$

$I N I R G_{R, R G}+$ newrg $_{R, R G} \leqslant R G T_{R}$

The RPS target is a minimum proportion of renewable electricity in total electricity generation. As shown in Eq. (15), the target for each LPS can be met by locally generating renewable electricity or purchasing RECs externally. The surplus generated renewable electricity can be sold to other LPSs as RECs.

$$
\begin{gathered}
\sum_{D, H, R G} \operatorname{rgpp}_{D, H, R, R G} \times D A Y S_{D}+\sum_{R G, R^{\prime}}\left(\operatorname{recpf}_{R G, R, R^{\prime}}-\operatorname{recst}_{R G, R, R^{\prime}}\right) \leqslant \\
{\left[\sum_{D, H}\left(\sum_{N G} n g p p_{D, H, R, N G}+\sum_{R G} \operatorname{rgpp}_{D, H, R, R G}\right) \times D A Y S_{D}\right] \times R P S_{R}}
\end{gathered}
$$

In order to preclude arbitrage in REC scalping (which is explicitly prohibited in the National Development and Reform Commission's official notice [25]), a constraint on REC trading is added as Eq. (16), in which a LPS can only sell self-generated RECs.

$\sum_{R^{\prime}} \operatorname{recst}_{R G, R, R^{\prime}} \leqslant \sum_{D, H} \operatorname{rgpp}_{D, H, R, R G} \times D A Y S_{D}$

On the other hand, the hourly ramp-up and ramp-down constraints in the non-renewable power unit operations are considered in Eq. (17).

$\left(I N I N G_{R, N G}+\right.$ newng $\left._{R, N G}\right) \times R A M P D N_{N G} \leqslant n g p p_{D, H+1, R, N G}-n g p p_{D, H, R, N G} \leqslant$ $\left(I N I N G_{R, N G}+\right.$ newng $\left._{R, N G}\right) \times R A M P U P_{N G}$

\subsection{Interregional power market and REC market}

In addition to the optimization objective of each LPS, marketclearing conditions are needed to equilibrate supply and demand in both power market and REC market, which are shown as Eqs. (18) and (19), respectively. The power price (powpri) and REC price (recpri) are the dual variables utilized in the market-balancing equations. The power market is settled in real-time and the REC market is settled once per year.

$p s t_{D, H, R, R^{\prime}}=p p f_{D, H, R^{\prime}, R}$

$\operatorname{recst}_{R G, R, R^{\prime}}=\operatorname{recpf}_{R G, R^{\prime}, R}$

\subsection{Complementarity model}

The proposed multi-region power market model can be solved as a mixed complementarity problem (MCP). Since the objective functions are quadratic and all the constraints are linear, the Karush-Kuhn-Tucker (KKT) conditions of the MCP are sufficient for the optimization of the objective function [26]. The further mathematical properties of existence and uniqueness for the MCP solution can be found elsewhere 
$[27,28]$. In the present study, the MCP problem is programmed in the General Algebraic Modeling System (GAMS) [29] and solved using the PATH solver [30].

\section{Data and assumption}

\subsection{Data}

The input data of the proposed model include installed power plant capacity, electricity demand, weather conditions and the RPS targets all at province level. The electricity demand and weather condition data are at 3-hour average. For example, the wind speed of the first number in the time series is the average of that in actual three hours (from 0:00 am to 3:00 am), and so forth. In our proposed model, variables such as the power generation amount in each time series have been multiplied by 3 , and the $24 \mathrm{~h}$ data in each day are considered in this way. Three seasonal climate-related representative days are considered in the present study: a summer day (representing May to August, 123 days in total), a winter day (representing November to January, 92 days in total) and a mid day (representing February to April, September and October, 150 days in total).

The data about interregional transmission capacity, efficiency and price, the future cost of technologies and fuels, and emission factors of power plants. are from previous studies [24,31], as listed in Appendix A.

\subsubsection{Electricity demand}

Regional electricity demand is influenced by the population growth, economic prosperity and other factors. A detailed prediction of regional power demand is conducted based on the future possible macroeconomic slowdown given in [24]. The forecast regional electricity demand to 2020 [32] is shown in Fig. 2.

\subsubsection{Capacity mix of existing power plants}

The data for existing power plants, covering resource type, capacity, and location, was from the China Electricity Council [17]. The capacity mix of in 2015 is shown in Fig. 3.

\subsubsection{Capacity factor for renewable power generators}

The capacity factors of renewable power plants are decided by regional climatic conditions such as wind speed, solar irradiation, and temperature. The maximum capacity factor for wind power and PV power in each region is shown in Fig. 4. These weather climatic data were obtained from the NASA Langley Research Center Atmospheric Science Data Center Surface meteorological and Solar Energy (SSE) web portal supported by the NASA LaRC POWER Project. [33].

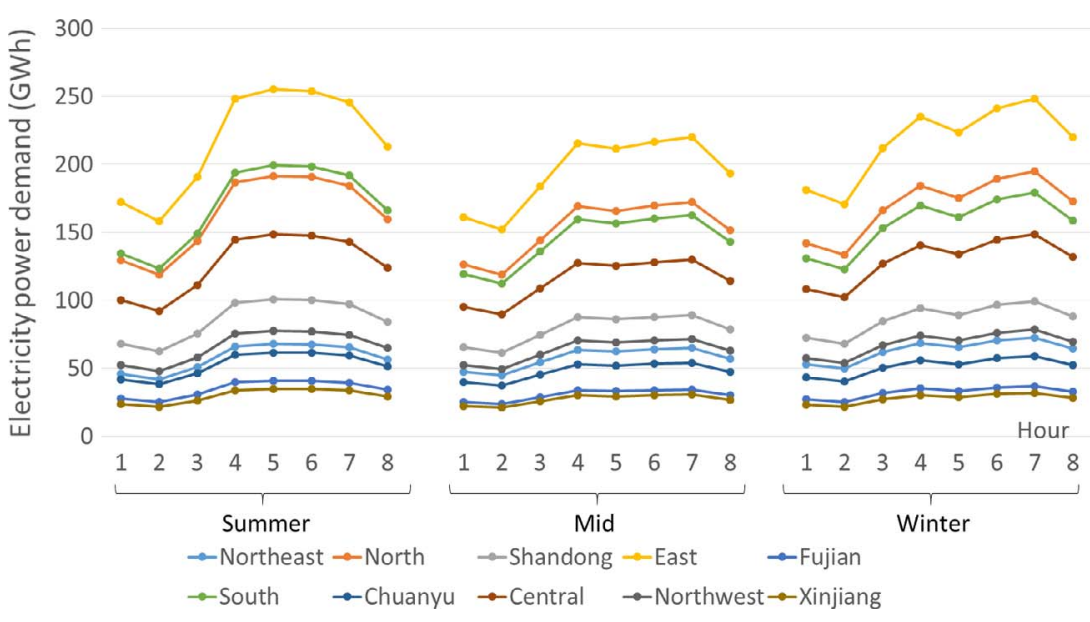

\subsubsection{Policy and regulation}

The 2020 RPS target at province level is published by China's National Energy Administration [12] as shown in Table 1.

In China, the price for electricity generated from different resources are regulated by the National Development and Reform Commission $[34,35]$. The latest regulated benchmark power price for coal, PV and wind power are shown in Fig. 5. Compared to coal, wind power and PV are higher, which are in a range of $0.02-0.27 \mathrm{RMB} / \mathrm{kWh}$ and $0.27-0.55 \mathrm{RMB} / \mathrm{kWh}$ respectively.

\subsection{Scenario proposal}

To investigate the effect of using RPS and REC trading to substitute FIT, six scenarios representing different policy combinations are proposed as shown in Table 2.

\section{Results}

\subsection{Development of renewable energy}

The total new renewable power capacity in the whole country under each scenario is shown in Table 3. When there is no FIT policy nor RPS policy (in NFNRNT scenario), no new renewable power capacity will be installed. When there is only FIT policy (in FNRNT scenario), $78.6 \mathrm{GW}$ new PV capacity and $27.5 \mathrm{GW}$ new wind capacity will be installed, and 183.4 GW more PV capacity and $25.6 \mathrm{GW}$ more wind capacity are needed to meet the upcoming RPS targets (in FRNT scenario). That is because the intermittence of renewable power induces a back-up cost when connecting to the power grid. The back-up cost comes from two aspects: (1) the fossil power generators need to reduce the capacity factors so that the renewable power can be fed into the power grid; (2) the outputs of fossil power generators need to be adjusted whenever the outputs of renewable power generators varied. The back-up cost is so high that current FIT subsidies cannot support the renewable power to fully compete with non-renewable power in the market. The same reason leads to a high curtailment ratio of wind power and PV power in reality.

Comparing scenarios with FIT (i.e. FRT and FRNT) with those without FIT (i.e. NFRT and NFRNT), the new installed PV capacity reduces from $210.2 \mathrm{GW}$ and $262 \mathrm{GW}$ to 0 and $76.0 \mathrm{GW}$ respectively, while the new installed wind capacity increases from 0 and $53.1 \mathrm{GW}$ to 162.4 GW and 171.2 GW respectively. It can be identified that the RPS plays the crucial role in promoting the installation of wind power capacity, while the FIT subsidy is better for developing PV. The reason is that FIT subsidy is different for various power generation technologies, while the RPS policy treats the expensive technology like PV equally to the cheaper technology like wind.
Fig. 2. Regional electricity demand in three representative days in 2020. 


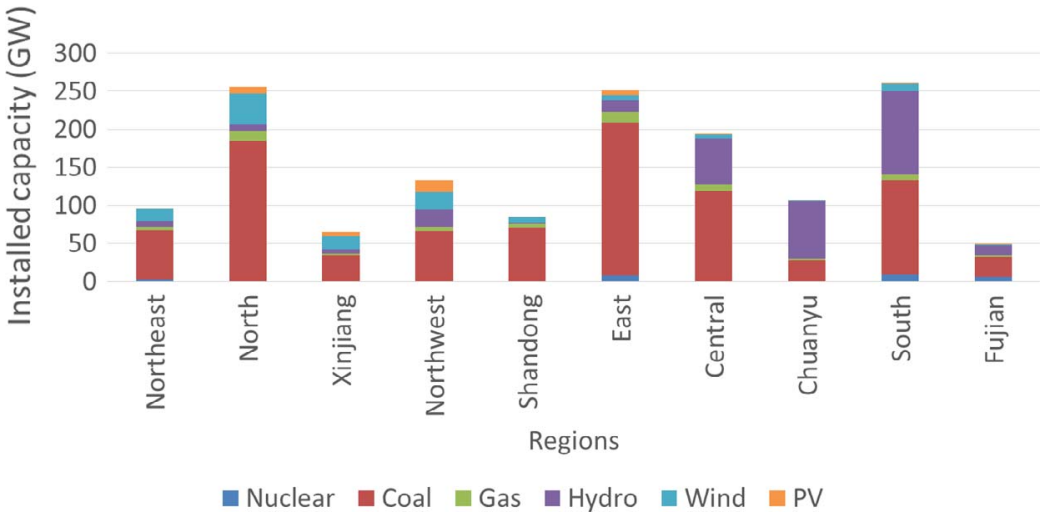

Fig. 3. Regional power capacity mix in 2015 .
When RPS policy is adopted together with REC trading (in scenarios of FRT and NFRT), only the more economic type of renewable power will be installed. When RPS policy is adopted without REC trading (in scenarios of FRNT and NFRNT), there are both new wind power capacity and PV power capacity installed. And the adoption of the FIT subsidy (in FRNT scenario) leads $186.0 \mathrm{GW}$ more PV power and 118.1 GW less wind power to be installed.

\subsection{Carbon emissions}

The total $\mathrm{CO}_{2}$ emissions of the power sector under different scenarios are depicted in Fig. 6. By comparing scenarios with FIT to those without FIT, it can be observed that RPS policy is more efficient to reduce carbon emissions, which is consistent to the findings of Sun [15], and FIT policy brings "rebound effect" in reducing carbon
Table 1

China's regional RPS target in 2020 .

\begin{tabular}{llllll}
\hline Region & Northeast & North & Xinjiang & Northwest & Shandong \\
\hline RPS target (\%) & $13 \%$ & $11 \%$ & $13 \%$ & $12 \%$ & $10 \%$ \\
Region & East & Central & Chuanyu & South & Fujian \\
RPS target (\%) & $7 \%$ & $7 \%$ & $5 \%$ & $7 \%$ & $7 \%$ \\
\hline
\end{tabular}

emissions when cooperating with a RPS policy. The FIT policy increases the total carbon emission by $3.8 \%$ when there is RPS policy with REC trade (compared FRT scenario with NFRT scenario), and by $2.7 \%$ when there is RPS policy without REC trade (compared FRNT scenario with NFRNT scenario). The "rebound effect" mainly arises from that the FIT policy can induce more PV capacity, which is more intermittent than

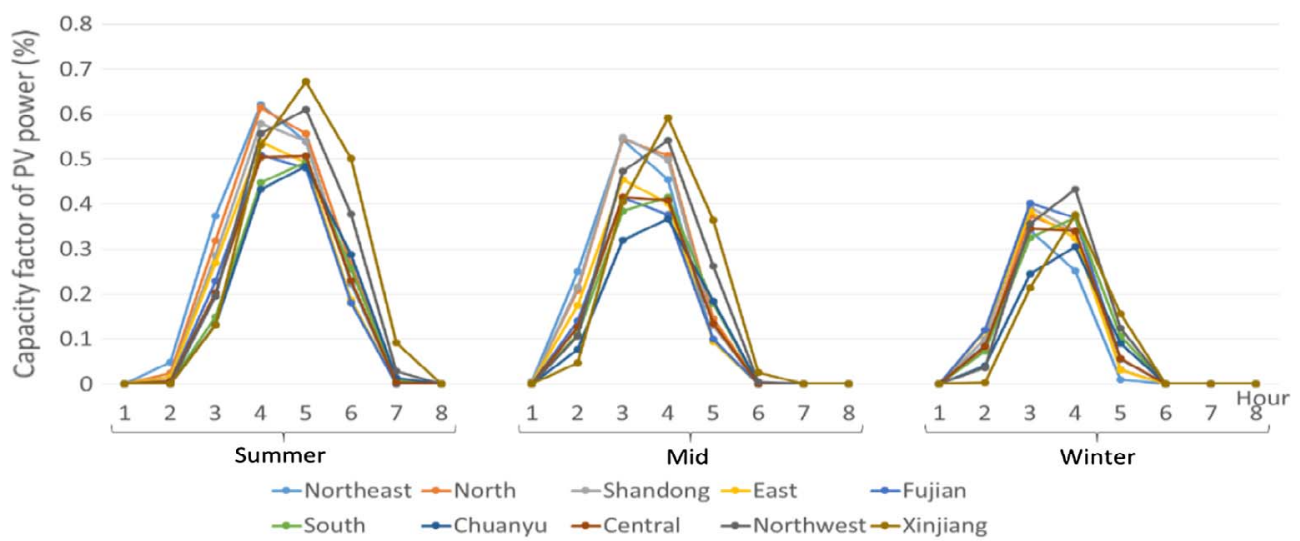

Fig. 4. Regional maximum capacity factor of renewable power plants.

(a) Capacity factor of PV power in three representative days
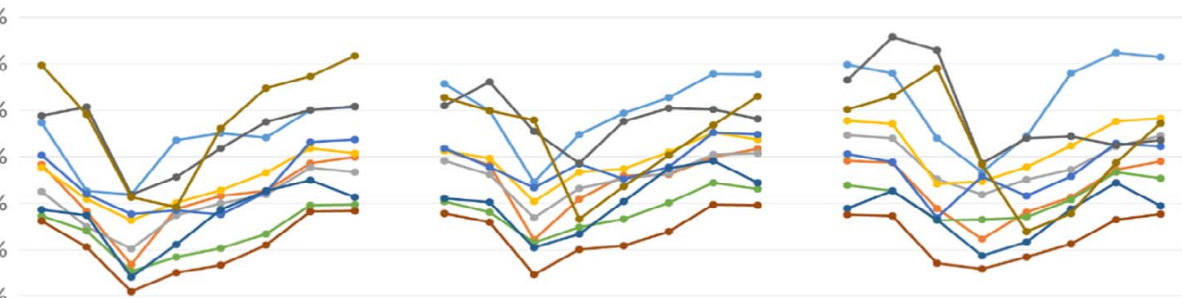

$5 \%$
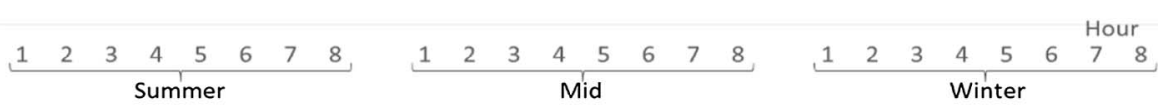

$\rightarrow$ Northeast $\rightarrow$ North $\rightarrow$ Shandong $\rightarrow$ East $\rightarrow$ Fujian

$\rightarrow$ South $\rightarrow$ Chuanyu $\rightarrow$ Central $\rightarrow$ Northwest $\rightarrow$ Xinjiang

(b) Capacity factor of wind power in three representative days 


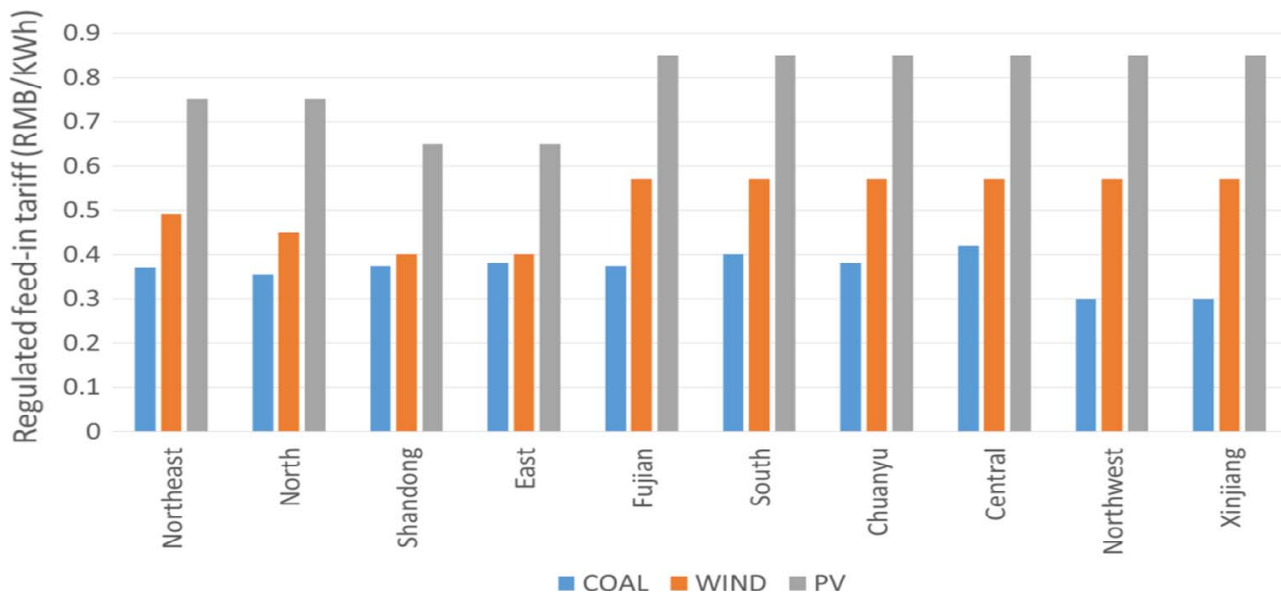

Fig. 5. Regulated benchmark power price in each region.

Table 2

Scenario set.

\begin{tabular}{llll}
\hline Scenario & \multicolumn{2}{l}{ Policy combination description } & \\
\cline { 2 - 4 } & FIT & RPS & REC Trade \\
\hline FRT & Yes & Yes & Yes \\
FRNT & Yes & Yes & No \\
FNRNT & Yes & No & No \\
NFRT & No & Yes & Yes \\
NFRNT & No & Yes & No \\
NFNRNT & No & No & No \\
\hline
\end{tabular}

Table 3

Total new renewable power capacity.

\begin{tabular}{lll}
\hline \multirow{2}{*}{ Scenario } & \multicolumn{2}{l}{ Total new renewable power capacity $(\mathrm{GW})$} \\
\cline { 2 - 3 } & $\mathrm{PV}$ & WIND \\
\hline FRT & 210.2 & 0 \\
FRNT & 262.0 & 53.1 \\
FNRNT & 78.6 & 27.5 \\
NFRT & 0 & 162.4 \\
NFRNT & 76.0 & 171.2 \\
NFNRNT & 0 & 0 \\
\hline
\end{tabular}

wind power and thus needs more fossil power to back up as base load especially during the night.

\subsection{Social welfare}

Profits of each local power sector are depicted in Fig. 7. The RPS policy can decrease the power sector's profit because obligatory proportions of renewable power are imposed on the power sector. The REC trading can further decrease the power sector profit because the generated renewable electricity that is counted as the tradeable RECs cannot receive the FIT subsidy. Compared to the scenario where there is only FIT policy (FNRNT), the RPS policy without REC trade (scenario FRNT) can decrease the total profit by $42.3 \%$, and the RPS policy with REC trade (scenario FRT) can decrease the total profit by $49.5 \%$. Compared to the scenario where there is no renewable power promotion policy (NFNRNT), the RPS policy without REC trading (scenario NFRNT) can decrease the total profit by $71.1 \%$, and the RPS policy with REC trading (scenario NFRT) can decrease the total profit by $118.2 \%$.

The equilibriums of REC markets under different scenarios are described in Table 4. Under the FIT subsidy (scenario FRT), the PV REC price will be higher than the Wind REC price because the FIT subsidy for PV power is higher than that for wind power. Since PV REC and Wind REC are homogeneous for the RPS target, PV RECs cannot compete with Wind RECs. And therefore, there are only Wind RECs in REC trading market in scenario FRT. The market scale is 15.2 billion RMB and the REC price is $174.6 \mathrm{RMB} / \mathrm{MWh}$. When there is no FIT (scenario NFRT), there are both Wind RECs and PV RECs in REC trading market, whose market scale are 91.2 billion RMB and 8.4 billion RMB, respectively. The equilibrium REC price is $207.8 \mathrm{RMB} / \mathrm{MWh}$, which is

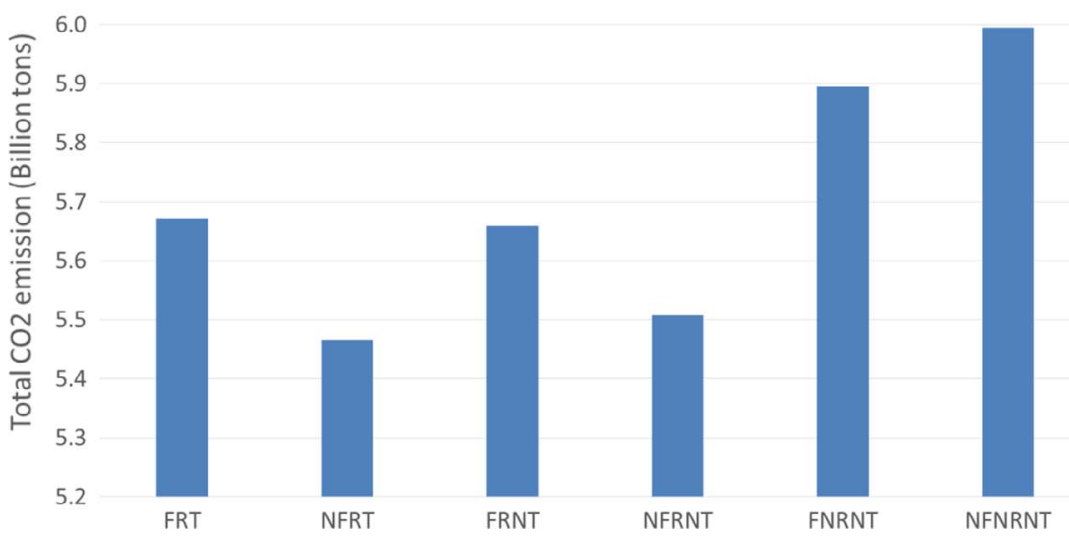




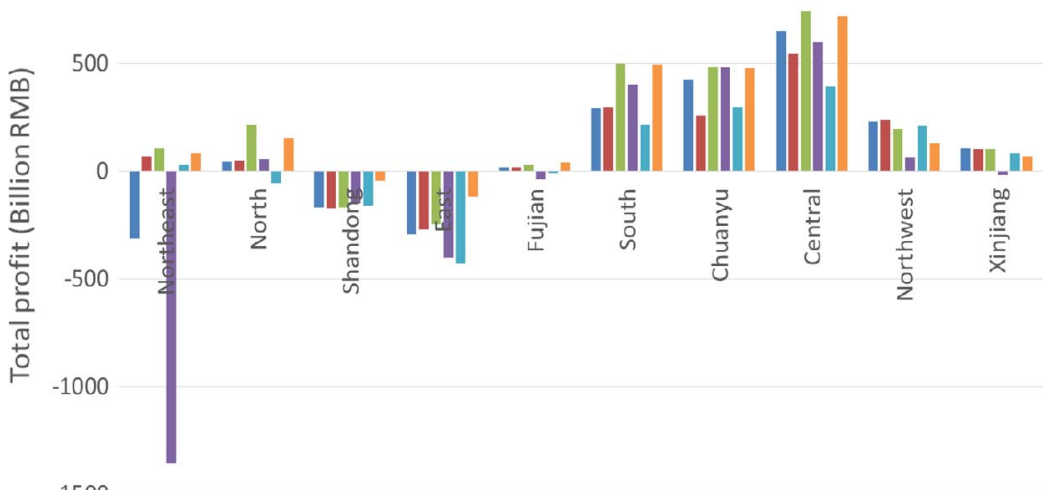

$-1500$

$\square$ FRT $\square$ FRNT $\square$ FNRNT NFRT NFRNT NFNRNT

Table 4

REC trade market scale and equilibrium price.

\begin{tabular}{llll}
\hline Scenarios & Type & FRT & NFRT \\
\hline REC trade market scale (Billion RMB) & Wind & 15.2 & 91.2 \\
& PV & 0 & 8.4 \\
REC trade equilibrium price (RMB/MWh) & Wind & 174.6 & 207.8 \\
& PV & - & 207.8 \\
\hline
\end{tabular}

19.0\% higher than the price under the FIT subsidy. Similar to the results in [36], for wind power, the REC price is close to the current FIT subsidy; while for PV power, the FIT subsidy is much higher.

The government's expenditure on subsidizing renewable energy projects via the FIT was shown in Fig. 8. It demonstrates that the RPS policy will increase the government's expenditure by $92.3 \%$ unless the REC trading is implemented simultaneously. The total expenditure of the scenario FRT is 897.2 billion RMB, which is $14.1 \%$ lower than that of scenario FRNT. With REC trading (scenario FRT), $66.8 \%$ of the government's expenditure on subsidizing renewable projects are reduced in the Central and Chuanyu regions. Central and Chuanyu regions have the least renewable energy resources, which means that the FIT subsidy for these regions is inefficient and REC trade can improve the subsidy efficiency.

Previous studies usually ignored analyzing the government's expenditure on FIT subsidy for renewable energy, which is one of the contribution of this study. As shown in Table 5, the government's average expenditure on FIT subsidy for renewable energy, calculated as the total FIT subsidy divided by the total renewable energy capacity, which represent the subsidy efficiency of the government, vary in
Table 5

Government's average expenditure on FIT subsidy for renewable energy (Billion RMB/ GW).

\begin{tabular}{llll}
\hline Scenarios & FRT & FRNT & FNRNT \\
\hline Average investment & 4.27 & 3.3 & 5.12 \\
\hline
\end{tabular}

different policy scenarios. When there is only FIT (under FNRNT scenario), the government's average investment is 5.12 billion RMB/GW, which is the lowest efficiency scenario. And under scenario FRNT, the government's average investment is 3.31 billion RMB/GW, which is the most efficient.

\section{Conclusions}

To afford the expenditure on subsidizing renewable energy projects via the FIT caused heavy financial burdens for governments all over the world. The present study proposed a multi-region power market model for all nations and quantified the substitution effects of regional RPS targets and interregional REC trade for the FIT on the power system, environment and social welfare. As a case study, the model has been applied to China considering the case of the upcoming 2020 RPS target and REC trading. Based on the obtained results, it is concluded:

(i) RPS with REC trading can only promote the development of wind power which is the most economic renewable energy technology, while FIT can promote more expensive renewable energy technology like PV power;

(ii) Excluding FIT policy decreases $2.7-3.8 \%$ carbon emission when
200

\section{0}

160
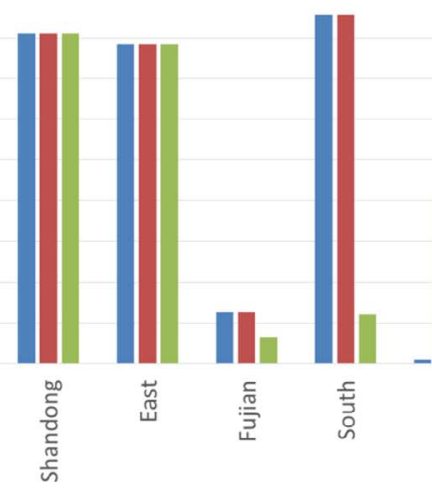

aRT $\square$ FRNT $\square$ FNRNT

Fig. 8. Government subsidy investment. 
adopting the RPS policy, and such "rebound effect" arises from the installation of more PV power capacity, which is more intermittent and thus needs more backup fossil power;

(iii) When there is FIT, only Wind RECs are traded in the market, which means that PV projects prefer FIT subsidy. Excluding FIT subsidy can increase the price of REC by $19.0 \%$ and increase the scale of REC market by $555.3 \%$;

(iv) Excluding FIT decreases the power sector's profit by $136.8 \%$ when adopting RPS policy and REC trade, which means the power sectors will suffer losses without FIT subsidy;

(v) When there is FIT, implementing RPS policy can increase the efficiency of FIT subsidy by $80.4 \%$ although increase government's expenditure by $92.3 \%$. Furthermore, adopting REC trade market can reduce $14.1 \%$ of government expenditure on FIT subsidy for renewable projects to meet RPS targets.

\section{Appendix A. Parameters imported from previous studies}

See Tables 6-9.

Table 6

Transmission efficiency (\%).

\begin{tabular}{|c|c|c|c|c|c|c|c|c|c|c|}
\hline & Northeast & North & Xinjiang & Northwest & Shandong & East & Central & Chuanyu & South & Fujian \\
\hline Northeast & - & 95.9 & - & - & - & - & - & - & - & - \\
\hline North & 95.9 & - & - & 97.3 & 98 & - & 96.4 & - & - & - \\
\hline Xinjiang & - & - & - & 95.1 & - & - & - & - & - & - \\
\hline Northwest & - & 97.3 & 95.1 & - & - & - & 96.5 & 98.1 & - & - \\
\hline Shandong & - & 98 & - & - & - & 97.7 & 97.7 & - & - & - \\
\hline East & - & - & - & - & 97.7 & - & 97.9 & - & - & 98 \\
\hline Central & - & 96.4 & - & 96.5 & 97.7 & 97.9 & - & 97 & 96.7 & 97.8 \\
\hline Chuanyu & - & - & - & 98.1 & - & - & 97 & - & 97.1 & - \\
\hline South & - & - & - & - & - & - & 96.7 & 97.1 & - & 96.4 \\
\hline Fujian & - & - & - & - & - & 98 & 97.8 & - & 96.4 & - \\
\hline
\end{tabular}

Table 7

Transmission price (RMB/MWh).

\begin{tabular}{|c|c|c|c|c|c|c|c|c|c|c|}
\hline & Northeast & North & Xinjiang & Northwest & Shandong & East & Central & Chuanyu & South & Fujian \\
\hline Northeast & - & 30 & - & - & - & - & - & - & - & - \\
\hline North & 30 & - & - & 20 & 15 & - & 27 & - & - & - \\
\hline Xinjiang & - & - & - & 37 & - & - & - & - & - & - \\
\hline Northwest & - & 20 & 37 & - & - & - & 26 & 14 & - & - \\
\hline Shandong & - & 15 & - & - & - & 17 & 17 & - & - & - \\
\hline East & - & - & - & - & 17 & - & 16 & - & - & 15 \\
\hline Central & - & 27 & - & 26 & 17 & 16 & - & 23 & 25 & 17 \\
\hline Chuanyu & - & - & - & 14 & - & - & 23 & - & 22 & - \\
\hline South & - & - & - & - & - & - & 25 & 22 & - & 27 \\
\hline Fujian & - & - & - & - & - & 15 & 17 & - & 27 & - \\
\hline
\end{tabular}

Table 8

Transmission capacity (GW).

\begin{tabular}{|c|c|c|c|c|c|c|c|c|c|c|}
\hline & Northeast & North & Xinjiang & Northwest & Shandong & East & Central & Chuanyu & South & Fujian \\
\hline Northeast & - & 17.4 & - & - & - & - & - & - & - & - \\
\hline North & 17.4 & - & - & 25.2 & 50 & - & 10 & - & - & - \\
\hline Xinjiang & - & - & - & 50.951 & - & - & - & - & - & - \\
\hline Northwest & - & 25.2 & 50.951 & - & - & 26.9 & - & 30.2 & 6 & - \\
\hline Shandong & - & 50 & - & - & - & 3.5 & - & - & - & - \\
\hline East & - & - & - & 26.9 & 3.5 & - & 41.5 & - & - & 50 \\
\hline Central & - & 10 & - & - & - & 41.5 & - & 50 & 3.5 & - \\
\hline Chuanyu & - & - & - & 30.2 & - & - & 50 & - & - & - \\
\hline South & - & - & - & 6 & - & - & 3.5 & - & - & - \\
\hline Fujian & - & - & - & - & - & 50 & - & - & - & - \\
\hline
\end{tabular}

Table 9

Cost and emission factor of power plants.

\begin{tabular}{|c|c|c|c|c|c|c|}
\hline & Nuclear & Coal & Gas & Hydro & PV & Wind \\
\hline Capital costs (Billion RMB/GW) & 12.61 & 8.29 & 4.32 & 30.62 & 13.43 & 8.09 \\
\hline Operation-and-Maintenance costs (Billion RMB/GW) & 0.63 & 0.41 & 0.22 & 0.301 & 0.07 & 0.24 \\
\hline Variable costs (Billion RMB/GWh) & 0.00025 & 0.00028 & 0.00054 & 0 & 0 & 0 \\
\hline Emission factor (Thousand tons/GWh) & 0.066 & 1.055 & 0.448 & 0 & 0 & 0 \\
\hline Expected lifetime (years) & 40 & 45 & 45 & 60 & 20 & 20 \\
\hline
\end{tabular}




\section{References}

[1] REN21. Renewables 2016 global status report; 2016.

[2] Lo K. A critical review of China's rapidly developing renewable energy and energy efficiency policies. Renew Sustain Energy Rev 2014;29:508-16.

[3] Muhammad-Sukki F, Abu-Bakar SH, Munir AB, Mohd Yasin SH, Ramirez-Iniguez R, McMeekin SG, et al. Feed-in tariff for solar photovoltaic: The rise of Japan. Renew Energy 2014;68:636-43.

[4] Hillebrand B, Buttermann HG, Behringer JM, Bleuel M. The expansion of renewable energies and employment effects in Germany, Energy Policy 2006;34:3484-94.

[5] Muhammad-Sukki F, Ramirez-Iniguez R, Munir AB, Mohd Yasin SH, Abu-Bakar SH, McMeekin SG, et al. Revised feed-in tariff for solar photovoltaic in the United Kingdom: A cloudy future ahead? Energy Policy 2013;52:832-8.

[6] Wiser R, Barbose G, Holt E. Supporting solar power in renewables portfolio standards: Experience from the United States. Energy Policy 2011;39:3894-905.

[7] Lesser JA, Su X. Design of an economically efficient feed-in tariff structure for renewable energy development. Energy Policy 2008;36:981-90.

[8] Böhringer C, Keller A, van der Werf E. Are green hopes too rosy? Employment and welfare impacts of renewable energy promotion. Energy Econ 2013;36:277-85.

[9] Pyrgou A, Kylili A, Fokaides PA. The future of the Feed-in Tariff (FiT) scheme in Europe: The case of photovoltaics. Energy Policy 2016;95:94-102.

[10] Guo X, Liu H, Mao X, Jin J, Chen D, Cheng S. Willingness to pay for renewable electricity: A contingent valuation study in Beijing China. Energy Policy $2014 ; 68: 340-7$.

[11] Li Y, Mu X, Schiller AR, Zheng B. Willingness-to-pay for climate change mitigation: evidence from China; 2015.

[12] National Energy Administration. Guidance on the establishment of the target system for the development and utilization of renewable energy resources; 2016

[13] Lewis JI, Wiser RH. Fostering a renewable energy technology industry: An international comparison of wind industry policy support mechanisms. Energy Policy 2007;35:1844-57.

[14] Cory KS, Couture T, Kreycik C. Feed-in tariff policy: design, implementation, and RPS policy interactions. National Renewable Energy Laboratory; 2009.

[15] Sun P, Nie P. A comparative study of feed-in tariff and renewable portfolio standard policy in renewable energy industry. Renew Energy 2015;74:255-62.

[16] Tamás MM, Bade Shrestha SO, Zhou H. Feed-in tariff and tradable green certificate in oligopoly. Energy Policy 2010;38:4040-7.

[17] Mack JH, Gianvecchio N, Campopiano MT, Logan SM. All RECs are local: how instate generation requirements adversely affect development of a robust REC market. Electr J 2011;24:8-25.
[18] Berendt CB. A state-based approach to building a liquid national market for renewable energy certificates: The REC-EX model. Electr J 2006;19:54-68.

[19] Perez AP, Sauma EE, Munoz FD, Hobbs BF. The economic effects of interregional trading of renewable energy certificates in the U.S. WECC. Energy J 2016;37.

[20] Yin H, Powers N. Do state renewable portfolio standards promote in-state renewable generation?. Energy Policy 2010;38:1140-9.

[21] Morris J, Reilly JM, Paltsev S. Combining a renewable portfolio standard with a cap-and-trade policy: a general equilibrium analysis. MIT Joint Program on the Science and Policy of Global Change; 2010.

[22] Tanaka M, Chen Y. Market power in renewable portfolio standards. Energy Econ 2013;39:187-96.

[23] Chen Y, Wang L. Renewable portfolio standards in the presence of green consumers and emissions trading. Netw Spat Econ 2013;13:149-81.

[24] Cheng R, Xu Z, Liu P, Wang Z, Li Z, Jones I. A multi-region optimization planning model for China's power sector. Appl Energy 2015;137:413-26.

[25] National Development and Reform Commission, Ministry of Finance of the People's Republic of China, National Energy Administration. Notice on implementation of renewable green power certificate issuance and voluntary subscription system; 2017.

[26] Gabriel SA, Conejo AJ, Fuller JD, Hobbs BF, Ruiz C. Complementarity modeling in energy markets, vol. 180, Springer Science \& Business Media; 2012.

[27] Tung C-P, Tseng T-C, Huang A-L, Liu T-M, Hu M-C. Impact of climate change on Taiwanese power market determined using linear complementarity model. Appl Energy 2013;102:432-9.

[28] Gabriel SA, Kiet S, Zhuang J. A mixed complementarity-based equilibrium model of natural gas markets. Oper Res 2005;53:799-818.

[29] Rosenthal RE. GAMS-a user's guide; 2004.

[30] Ferris MC, Munson TS. GAMS/PATH user guide; 2000.

[31] Zhang Q, Mclellan BC, Tezuka T, Ishihara KN. An integrated model for long-term power generation planning toward future smart electricity systems. Appl Energy 2013;112:1424-37.

[32] China Electricity Council. Preliminary statistics of the national electric power industry; 2015.

[33] Stackhouse PW. Surface meteorology and solar energy; 2011.

[34] National Development and Reform Commission. Feed-in tariff for coal power; 2015

[35] National Development and Reform Commission. Feed-in tariff for PV and wind power. 2016

[36] Kwon T. Rent and rent-seeking in renewable energy support policies: Feed-in tariff vs. renewable portfolio standard. Renew Sustain Energy Rev 2015;44:676-81. 